\title{
Waste in the food system
}

By R. A. Lawrie, Food Science Laboratories, Department of Applied Biochemistry and Nutrition, University of Nottingham School of Agriculture, Sutton Bonington, Loughborough, Leics. LE $12{ }_{5} R D$

It is instructive to consider wastage in the food system in three consecutive phases: that of growth and harvesting, that of processing and preservation and that wherein the commodities are eaten and absorbed i.e. the realm of the consumer.

\section{Growth and harvesting}

Whether marine or terrestrial, food commodities commence with photosynthesis. Just outside the earth's atmosphere the sun's rays produce energy at the rate of $\mathrm{I} \cdot 3^{6 \mathrm{~kJ} \mathrm{~m}} \mathrm{~kJ}^{-2} \mathrm{~s}^{-1}$. In plants, the photosynthetic process requires about $17 \mathrm{~kJ}$ to produce I $g$ of dry matter; and were the solar radiation available at the edge of the earth's atmosphere to be used with 100\% efficiency, it would yield 2.6 tons/square metre per year (Monteith, 1972). Actual yields of agricultural crops range from only $0.004 \%$ to $0.2 \%$ of the theoretical maximum: the UK average is $0.16 \%$ (Anon, 1976a). This is due to such factors as latitude and season, the clarity of the atmosphere, the spectral composition of the radiation available and leaf areas and arrangement (Monteith, 1972). Organic wastes from the crop biomass and from domestic sewage amount to $4 \%$ of the primary energy requirement in UK. The growth of photosynthetic aquatic micro-organisms (e.g. on moorland, coastal regions) could convert such material into fuel, thus indirectly enhancing the efficiency of the food production system (Anon, I976a).

Nitrogen is the principal limiting nutrient for plant growth. In legumes the symbiotic association between root nodules and nitrogen-fixing bacteria, represents a self-replenishing nitrogenous system; and a current aim of so-called genetic engineering is to introduce the capacity of nitrogen fixation into plants such as the cereals so that the staple crops would more effectively utilize a given acreage of land surface to produce nourishing foodstuffs. This is long-term, however. In the short term, there is greater potential for exploring the discovery that some free-living, nitrogen-fixing micro-organisms can form close associations with crop roots (Duckham, Jones \& Roberts, 1976).

The detection and correction of drought, flood, soil deficits or excess and incipient disease is another aspect of avoiding wastage in the realms of plant growth. The possibility of such control has enormously increased with the introduction of artificial satellites, such as Landsat, which from a height of 500 miles can monitor the entire surface of the earth swiftly and frequently. Early detection by such means of drought will afford the means of limiting crop wastage $36(3) 4$ 
through climatic and environmental factors and permit prophylactic action against such biological hazards as locust swarms by giving early warning of developing centres of these pests (Loftus, 1977). A large swarm of locusts can destroy 80000 tons of food daily. Five per cent of the world's crops are lost through insect infestation and $7 \%$ through microbial diseases. In UK annually, quite apart from the action of insects and weeds, plant diseases cause the loss of about $8 \%$ and $14 \%$ of the wheat and barley crops respectively; and a loss of $£_{3} 000000$ in the crop of strawberries. Apples, pears and plums worth 64000000 are lost through bird damage (Anon, 1975). Great progress has been made since the 1939-45 war in the use of pesticides to control or prevent such wastage, but it is still formidable.

The phase of harvesting is associated with a surprisingly great amount of wastage. Thus, a considerable percentage of sugar beet and potatoes is left unharvested on, or in, the ground; potatoes also suffer considerable damage at harvesting; threshing losses diminish the return from cereals; and the yield of such crops as peas and beans is lowered by faulty design in viners and bean pickers. In UK alone, it has been estimated that avoidable losses associated with harvesting machinery total about $9 \%$ of the grown crops: and cost more than $£_{100} 000000$ per year (Theophilus, 1977).

In respect of food commodities derived from animals, there is also considerable wastage in the period from conception to slaughter. For example about $10 \%$ of eggs suffer cracks and breakages between farms and wholesalers, which downgrade their value and render them more liable to microbial spoilage. Such wastage costs $f_{5} 000000$ annually in UK alone (Anon, 1975).

Various aspects of reproductive failure in cattle, sheep, pigs and poultry have been estimated to cost Britain about $\oint_{1} 75000000$ a year (Anon, 1975).

The benefits of artificial insemination, whereby highly desirable characteristics of a particular sire can be vastly extended, in time and location, beyond naturallyset limits, are frequently not attained in practice. Thus, in the past, ovulation and insemination have been out of phase. Now that means of synchronizing them are available, conception rates in artificial insemination should increase very greatly.

However inefficient animals may be in comparison with plants and microorganisms in producing food, ruminants in particular have the capacity to convert the sparse vegetation of the vast area of land which is unsuitable for agriculture (or too remote for the complex infrastructure required for controlled microbial fermentation) into edible tissue of excellent biological value (Blaxter, 1968).

The returns from many areas of currently grazed land could be enhanced by greater exploitation of indigenous, if relatively unfamiliar species, such as members of the antelope family in the dry tropics and the water buffalo in the wet tropics. They could also be enhanced by judicious mixing of different species whereby the plant growth of a given area was more fully utilized, the various species eating different types or parts of plants, and consuming foliage at different levels above the ground (Kyle, 1972).

Under domestication, it is now apparent that the ruminant can synthesize amino acids from inorganic nitrogen such as urea, and that hitherto waste material such 
as straw and manure, can also be utilized (Anthony, 1969). Poultry manure (800000 tons is produced annually in UK (Rolfe, 1976)) contains two to three times the quantity of essential amino acids found in that of cattle or pigs, and thus can be used directly as feed. Cattle and pig manure has an initial protein content of about $5 \%$. This can be upgraded to $13 \%$ and its content of essential amino acids trebled, by fermentation by thermophilic fungi, with the concomitant utilization of straw as energy source (Seal \& Eggins, 1976). In this way micro-organisms can bypass natural processes involving photosynthesis and return nutrients to animals more directly and efficiently. Since rumen microflora can degrade essential amino acids and prevent their absorption, treatments to protect them against such destruction have been devised. Thus, formalin-treated feed prevents rumen microorganisms from attacking its amino acids and permits their subsequent absorption from the small intestine (McDonald, I968).

In the case of non-ruminants, such as pigs and poultry, the economic synthesis of essential amino acids by the chemical industry has enabled their addition to feed from which their natural absence lowers the biological value of the proteins. This circumstance has greatly increased the efficiency of utilization of feed which would otherwise fail to produce optimum growth; but it has also led to a recognition that excess provision of one essential amino acid can lower the efficacy of others (Harper \& Benevenga, 1970), and, thereby, to the means of avoiding wasteful amino acid imbalance.

Excessively fat animals used to be commonplace, and dominated the show ring. The feeding policy to which this was due has changed markedly in recent years. The high cost of depositing fat in flesh is now more clearly appreciated. Smaller families and changed social conditions have operated against the popularity of fat joints (most consumers now cut off excess fat when eating meat). An alleged causative relationship between the consumption of animal fats and cardiovascular disease has been publicised. Increasingly, therefore, meat animals are slaughtered before they enter the (wasteful) fattening phase of growth. In respect of feeding generally, even a modest improvement in the efficiency of conversion into flesh would yield substantial benefits. Thus a $1 \%$ decrease in the amount of feed required in the areas of milk production, beef, pork and poultry would save f1 8000000 annually in UK (Anon, 1975).

Much wastage of meat occurs between the period when animals attain saleable weight and the moment of slaughter. Only relatively recently has it been suggested that preslaughter stress can lead to poor meat quality and even condemnation of the carcase. Such preslaughter stress, which may be psychological as well as physiological, can so deplete reserves of muscle glycogen that lactic acid fails to be produced adequately during post-mortem glycolysis. The resultant high $\mathrm{pH}$ causes discolouration, poor flavour and an increased tendency for microbial spoilage during meat storage. Stress can also cause an abnormally fast rate of lactic acid production post mortem, leading to massive exudation and poor manufacturing quality. Such stress also exacerbates the ease of invasion of bacteria from the gut into the animal's blood stream, and hence the tendency for meat spoilage. 
More overt aspects of preslaughter stress in handling animals en route to abbatoir arise in transport from bruising, oedema and emaciation. The magnitude of the wastage due to this factor can be judged by the fact that in $197 \mathrm{r}, 65$ and $77 \%$ of the total condemnation of sheep and cattle carcases respectively in Northern Ireland were attributable to those causes (Melrose \& Gracy, 1975). Again, death of pigs in transport appears to have increased greatly in the decade 1960-1970 (Thornton, 1973), possibly as a reflection of the concentration of slaughtering in fewer abattoirs and of the increased use of mechanized transport.

Disease in animals at time of slaughter, due to bacterial infections or parasitic infestations, is another cause of carcase condemnation and wastage. Such disease can be acquired on the farm, in transit or during preslaughter holding. For example, between outright carcase condemnation and downgrading of quality, liver fluke alone caused a loss of $f_{1} 500000$ annually in England and Wales (Melrose \& Gracy, 1975). Tuberculosis, brucellosis and salmonellosis, and diseases due to various parasitic worms, are among other causes of extensive but avoidable carcase wastage.

As another facet of waste avoidance in food production there is heightened interest in reconsidering fish farming in a modern context. Although sea fishing is an adventitious, harvesting operation, controlled fish production in restricted volumes of water is an ancient, unsophisticated and highly efficient means of producing food. The use of the warm water from the cooling towers of power stations to accelerate the growth of fish is a reflection of UK efforts to maximize the use of fuel and space, which is currently wasted.

\section{Processing and preservation}

The phase of preservation and processing in food systems might reasonably be expected to exclude wastage automatically. But such is not the case because neither preservation procedures nor the human beings who apply them are faultless. Of course, improvement in preservative techniques are continually being made as new knowledge of shortcomings and of their nature permits their avoidance. But much qualitative and quantitative wastage continues to occur at this stage in commodity history. It is important to recognize that saving in one respect may cause wastage in another. Thus, the conditions needed to ensure that microbiological action is prevented, may enhance physico-chemical wastage. Nutritive value may be lowered by over-heating of canned meats; flavour quality may be impaired in prolonged pasteurising or sterilizing of milk; texture may be worsened by dehydrating vegetables. Forty years ago, attempts to avoid wastage in bacon manufacture by concentrating its production in larger factories, led to increased transport fatigue in pigs, a lower degree of acidity in the flesh post mortem and, thereby, to enhanced wastage because of 'fiery' discoloration and microbial spoilage in the commodity. Again the use of more efficient refrigeration plant in New Zealand abbatoirs led to diminished meat quality. These saved space and time in preparing frozen lamb, but caused severe toughness because they brought about a hitherto unknown phenomenon referred to as 'cold-shortening'. 
In recent years there has been a vast increase in the application of refrigeration, chilling and freezing, in handling food commodities. To a considerable extent this has diminished much wastage which hitherto occurred, but the principles underlying the operation of the cold chain from producer to consumer have been imperfectly understood and haphazardly applied. Products have been stored at unsuitable refrigeration temperatures; they have been subjected to fluctuating conditions of temperature, ventilation and humidity; they have been placed in poorly designed vehicles for transport and stores for handling; and notwithstanding their nature and origin, they have been placed in juxtaposition for long periods whereby taints have become a significant problem. All these features have led to wastage.

Fruits, for example, insofar as their metabolism continues after harvesting, are susceptible to a considerable number of storage and market diseases which arise from the faulty matching of refrigeration to physiology (Hall \& Scott, 1969-73). Citrus and tropical fruits are especially sensitive to chilling and to wastage if temperatures are not strictly controlled. A difference of only $2^{\circ}$ can mean a difference of $30 \%$ in storage life (Anon, $1976 b$ ). The situation is exacerbated by the excessive use of plastic wrappings and containers (Hall \& Scott, 1969-73).

Again, in respect of the frozen storage of meat, it is still customary in UK to employ a temperature of $-10^{\circ}$ : yet weight losses by evaporation at $-30^{\circ}$ are only $20 \%$ of those at $-10^{\circ}$ (Cutting \& Malton, 1973). Moreover, wastage at the latter temperature increases the need to trim discoloured surfaces. Variation in the air temperatures operating in UK frozen stores has been found to range from $-2^{\circ}$ to $-36^{\circ}$.

The predilection for white bread in this country is automatically associated with waste in that, nutritionally, flours of higher extraction rate, which incorporate more of the original wheat grain, are of better nutritive value, having more protein and markedly more calcium and $B$ vitamins.

The procedures we adopt in preparing food for consumption involve considerable waste. According to McCance, Widdowson \& Shackleton (1936) there is a loss of $20-60 \%$ of the initial weight in trimming leafy vegetables. Corresponding values for root vegetables and fresh peas are $14-26 \%$ and $63 \%$ respectively. The loss of protein tends to be of the same order (Andross, 1946). $12-35 \%$ of the ascorbic acid is lost in peeling potatoes (Wager, 1945). Similar losses occur in dicing and mincing cabbage and salad greens (Walker \& Arvidsson, 1952). Waste in manufacturing operations includes such factors as the inadvertent production of substandard items which cannot command normal prices.

Irrespective of the mode of preservation or commodity, a major and continuing source of wastage arises from the faulty utilization by human consumers of commodities, due to their being the vehicle for food-borne disease. According to FAO, $80 \%$ of all human disease arise from water contaminated by microorganisms or parasites. In association with food there are 400000000 cases of enteritis annually; and parasites destroy 2000000 tons of human blood. Each year tapeworms alone involve the pointless diversion of ingested nutrients to produce 
r 00000 tons of protein which is worse than useless to the human host. In the temperate climate of UK the prevalence of such food-borne disease is less than in tropical areas; but it is a by no means negligible factor of wastage, leading to the condemnation of batches of commodities as well as the loss of that ingested in the food system. In UK the principal bacterial causes of food poisoning are Salmonellae (which proliferate in the human consumer), Staphylococci (which produce toxin in foods) and Clostridium welchii (which produce a toxin in the host's intestine). They are presumed to be respectively responsible for about 80,6 and $14 \%$ of the cases of food poisoning in this country (Hobbs, 1974).

Infection of foods by pathogens need not involve human agencies. Insects, vermin, birds and domestic animals can be the vehicles of contamination. Improvements in standards of hygiene would make a significant contribution to the degree of direct and indirect waste in food systems.

It can be estimated that $20000-200000$ tons of protein are wasted annually in UK abattoirs, as blood, lungs, stomachs and other portions of the carcase which are not customarily eaten. There is also a loss of 2-5\% of carcase protein in the effluents from abattoirs and poultry plants (Grant, 1976). By a combination of flocculation and ion-exchange procedures, New Zealand workers have demonstrated that 4.5 tons of protein of high quality can be recovered daily from a large abattoir using effluent containing $1000 \mathrm{ppm}$ protein. Similarly, in the dairy industry, about $\mathrm{I}-4 \%$ of milk inputs in dairies and creameries is lost as spillage, washings and drainage. At 1973 prices, this would represent an annual loss of between $\$ 7000000$ and $\$ 28000000$ (Coton, 1976). Such waste would be uneconomic to recover unless it was to be used as direct human food. On the other hand, a byproduct which could more readily be upgraded is whey. In 1973 UK produced 15000 tons of whey protein and 75000 tons of lactose. These are usually fed to animals, but techniques such as gel filtration are being used to concentrate whey protein and separate it from lactose, and if the latter could be effectively used, upgrading of whey would become economical.

\section{The consumer}

Ultimately, in commodity history, consumers' prejudices, behaviour and health contribute to underutilization and hence to waste. Although many of the most striking examples of food wastage and avoidable inanition are found overseas, custom and misconception also operate in UK.

One example is highlighted by the increasing difficulties of obtaining cod, which has long been the most widely consumed fish. Such fish as saithe and blue whiting (Micromesistius poutassou) are amongst the many species which are available in the seas around UK, which are largely underutilized because of aversion to such features as shape, and colour of flesh, but which are as palatable and nutritious as the more popular species (Keay \& Hardy, 1974).

Our national prejudices are not only irrational but inconsistent. Oysters used to be the fare of the very poor (Hollingsworth, 1958); and, in London, it was necessary to stipulate that apprentices should not be surfeited with fresh salmon. 
At that time the more fortunate citizens despised both sea foods. Now that they have become scarce extravagant organoleptic attributes are accorded to them. In UK the flesh of the horse is regarded as fit only for pet food, although it is highly nutritious and greatly prized in various countries abroad.

As alluded to previously wastage also arises from our failure to utilize fully the portions of carcases because they seem asthetically unattractive as originally presented. Although tripe and blood puddings are rightly prized in local areas in Britain, currently the majority of our citizens do not favour them; and indeed they are not regarded as permitted offal. Yet they contain protein of excellent biological value $-16-17 \%$ in lung, $12-15 \%$ in stomach, $7-13 \%$ in rumen, reticulum and omasum and $7-8 \%$ in blood plasma (Young \& Lawrie, 1974) especially if sources are mixed. By extraction and spinning into meat-like fibres, their nutritive value can be increased still further (Swingler, Neale \& Lawrie, 1977). It can be estimated that protein equivalent to about 200-250000 tons of meat could be produced annually in the UK from such normally wasted material. At the moment the vast majority exacerbates environmental pollution.

Similarly only about $60 \%$ of the landed weight of fish appears on the table: most of the remaining $40 \%$ could be preserved and presented as 'fish fingers' or in fish cakes of various kinds (Keay \& Hardy, 1974). The recent development of machines which can separate edible flesh from bone residues is an ancillary factor in waste avoidance.

Cooking contributes to loss of weight and of nutrients, but the effect depends on the mode adopted. Thus when cabbages are boiled $78 \%$ of the vitamin $C$ is retained, but when they are pressure cooked or fried the corresponding values are only $47-77 \%$ and $52 \%$ respectively (Patton \& Green, I954). After holding the cooked cabbage in steam for $2 \mathrm{~h}$ only $8 \%$ of the original vitamin $\mathrm{C}$ remains.

Institutional catering can involve wastage of food when meals, centrally cooked in bulk for large numbers, may fail to meet the preferences of individuals and may involve deterioration of quality due to long delays between the times and locations of cooking and consumption. The Leeds University/Hospitals 'Cook-Freeze' system permits large numbers of expertly cooked meals to be retained (in the frozen state) near optimal quality up to the time of consumption when they are reheated for the individual consumer (Anon, 1970). The system allows greater choice. In comparison with the conventional hospital 'hot-trolley, no choice' system, total wastage may be reduced from $47 \%$ to $33 \%$ of initial food weight. Concomitant retention of initial levels of vitamin $\mathrm{C}$ and of other nutrients is much greater. Again, a comparison of plate waste in school meals showed that the value was reduced by about $75 \%$ with the 'cook-freeze' system (Anon, 1974).

In fish frying the use of old thermally-oxidised cooking oil can cause $10 \%$ of the lysine in fish to become unavailable (Tooley \& Lawrie, 1974).

With meats, $15-40 \%$ of the vitamin $B_{1}$ is lost on boiling and $30-60 \%$ on roasting (Harris \& Von Loesecke, 1960). To a large extent, the consumer can limit wastage of various nutrients by careful selection of the most appropriate time, temperature and mode of heating for a particular commodity. 
Reference has already been made to disease and wastage arising from faulty hygiene; but, indeed, all human diseases involve wastage of nutrients-whether these are due to infectious agents, to carcinoma or to disorders of the circulatory, respiratory or digestive systems.

Misuse of specific nutrients arises in various genetic abnormalities of metabolism. These include the inability to metabolize carbohydrate at various stages and may lead to excessive deposition of polysaccharides in the tissues. Proteins may be wastefully utilized because of deficiencies in digestive enzymes, disturbances in intestinal amino acid transport, inborn errors of metabolism in respect of particular amino acid and protein intolerance (Carson, 1970). Obesity may be regarded as one aspect of faulty fat metabolism, although overeating is probably the major cause.

Even in the absence of disease, of course, there are vast differences between individual human beings in the machinery they have available to digest, absorb and utilize nutrients, and indeed, in their daily requirements for these (Williams, 1956). Our inability to match the individual's real requirements for nutrients with the amounts provided will continue to waste foodstuffs on a scale we cannot yet begin to assess.

\section{REFERENCES}

Andross, M. (1946). Proc. Nutr. Soc. 4, 155 .

Anon (1970). An Experiment in Hospital Catering using the Cook-Freeze System. University of Leeds: United Leeds Hospitals.

Anon (1974). Cook-Freeze in Practice. Liverpool: Liverpool Education Committee.

Anon (1975). Second Report of the Boards of the Foint Consultative Organization for Research and Development in Food and Agriculture. London: HM Stationery Öfice.

Anon (1976a). Solar Energy: its Potential Contribution within the United Kingdom (DES Energy Paper No. 16). London: HM Stationery Office.

Anon ( $1976 b$ ). Report of Working Group on Food Refrigeration (Science and Technology Board, JCO for R \& D in Agric. \& Food).

Anthony, W. B. (1969). Anim. Management Conf., Syracuse, N.Y.

Blaxter, K. L. (1968). Science F. 4, 53.

Carson, N. A. J. Jr. (1970). In Proteins as Human Food p. 458. [R. A. Lawrie, editor]. London: Butterworth.

Coton, S. G. (1976). In Food from Waste p. 221. [G. G. Birch, K. J. Parker and J. T. Worgan, editors]. London: Applied Science Publishers.

Cutting, C. L. \& Malton, R. (1973). ARC Meat Res. Inst. Memo no. 2.

Duckham, A. N., Jones, J. G. W. \& Roberts, E. H. (1976). In Food Production and Consumption: The Efficiency of Human Food Chains and Nutrient Cycles pp. 461, 487. Amsterdam: NorthHolland Publishing Co.

Grant, R. A. (1976). In Food from Waste p. 205 [G. G. Birch, K. J. Parker and J. T. Worgan, editors]. London: Applied Science Publishers.

Hall, E. G. \& Scott, K. J. (1969-73). C.S.I.R.O. Food Pres. Quart. Supplements.

Harper, A. E. \& Benevenga, N. J. (1970). In Proteins as Human Food p. 417. [R. A. Lawrie, editor]. London: Butterworth.

Harris, R. E. \& von Loesecke, H. (1960). Nutritional Evaluation of Food Processing. New York: John Wiley.

Hobbs, B. S. (1974). Food Poisoning and Food Hygiene 3rd Ed. London: Edward Amold.

Hollingsworth, D. (1958). The Englishman's Food, J. C. Drummond \& A. Wilbraham. Revised Edition by D. Hollingsworth p. 309. London: Jonathan Cape.

Keay, J. N. \& Hardy, R. (1974). Torry Mem. no. $46 \mathrm{I}$.

Kyle, R. (1972). Meat Production in Africa: The Case for a New Domestic Species. Bristol: University of Bristol Press. 
Loftus, A. (1977). Nero Scientist, p. 631.

McCance, R. A., Widdowson, E. M. \& Shackleton, L. (1936). Spec. Rep. Ser. Med. Res. Coun. no. 213 .

McDonald, I. W. (1968). Aust. Vet. F. 44, 145.

Melrose, D. R. \& Gracey, W. (1975). In Meat p. 109 [D. J. A. Cole and R. A. Lawrie, editors]. London: Butterworth.

Monteith, J. L. (1972). J. appl. Ecol. 9, 747.

Patton, M. B. \& Green, M. E. (1974). Ohio Agric. Exp. Sta., Res. Bull. no. 742.

Pyke, M. (1968). Foods and Society London: John Murray.

Rolfe, E. J. (1976). In Food from Waste p. I [G. G. Birch, K. L. Parker and J. T. Worgan, editors]. London: Applied Science Publishers.

Seal, K. J. \& Eggins, H. O. W. (1976). In Food from Waste p. $5^{8}$ [G. G. Birch, K. J. Parker and J. T. Worgan, editors]. London: Applied Science Publishers.

Swingler, G. R., Neale, R. J. \& Lawrie, R. A. (1977). Meat Sci. I, (In the Press.)

Theophilus, T. W. D. (1977). Agric. Engng Lond. 32, (1) 3.

Thornton, H. (1973). Textbook of Meat Inspection 2nd Ed. London: Bailliere, Tindall \& Cox.

Tooley, P. J. \& Lawrie, R. A. (1974). F. Fd. Technol. 9, 247.

Wager, H. G. (1945). Fd Mf. 20, 289.

Walker, A. R. P. \& Arvidsson, O. B. (1952). S. Afr. Y. med. Sci. 17, 143.

Williams, R. J. (1956). Biochemical Individuality. New York: John Wiley.

Young, R. H. \& Lawrie, R. A. (1974). F. Fd Technol. 9, 171.

Young, R. H. \& Lawrie, R. A. (1975). F. Fd Technol. 10, 453. 